\title{
Graphic Interface to Access a Multimedia Database on Spanish Emblematic Literature
}

\author{
Eva L. Iglesias \\ Nieves R. Brisaboa \\ Miguel R. Penabad \\ LFCIA - Facultad de Informática, Universidade Da Coruña \\ 15071 A Coruña. Spain \\ brisaboa@udc.es
}

\begin{abstract}
The advances in database technology allow us not only to store size-restricted numeric and alphanumeric data, but also Binary Large Objects. In our case, the database contains digitized Spanish Emblematic Literature books from XVI-XVIII centuries, as well as information extracted from these books. The database will be available on Internet through an HTML interface, which will allow us to send a query to the database through a form where the user specifies the searching conditions in a intuitive and friendly way for non-computing experts.
\end{abstract}

\section{Introduction}

Emblem books about morality started to be printed in the XVI century. Each emblem usually contains an image or emblem, an epigram - little poem explaining the idea the emblem tried to convey — and a text in prose which explains the idea quoting classical authorities and/or biblical episodes useful as examples.

Emblematic Literature, besides its literary interest, is a complex information source about society, morals, customs, etc., from XVI to XVIII century. At present to use these emblems as a research tool becomes an almost impossible task as most of them are widely scattered and only available in microfilms or microfiches.

\section{Database}

The multimedia database will store the digitized emblem books and lots of data resulting from the analysis of the books made by a team of experts on Latin, Arts, Philology, etc. Among the data there are: the most frecuently metaphores used to represent a particular concept; metrics used; key words; the most prolific printing places or dates; the most usual topics and their approach (for example, the kind of treatment given to women, ...), etc.

\section{User Interface to Access to Data}

In order to establish the link between the database and Internet we are developing a set of HTML pages accessible by any World Wide Web browser , e. g. Netscape. The "homepage" will provide links to other pages showing: general information about Emblematic Literature; a brief user guide and the database query interface.

This query interface is based on a form composed by a set of edition fields where the user can specify the searching conditions. One of the most useful searching fields is "Key Words" ( "politics", "woman", etc.), since it would allow experts on XVI-XVIII centuries' society to collect those emblems related to that matter.

The first information shown is the number of books, authors and emblems that satisfy the conditions. From here, users can see the rest of the retrieved information, simply following a set of hipertext links.

\section{Interface Implementation}

In order to connect Informix with the Internet interface it is necessary to establish a union "bridge" between them. So, we are developing a set of programs which are able to: retrieve the parameters corresponding to the searching conditions; generate the SQL commands from those parameters; and send them to Informix DBMS, capture the results and transfer them to an HTML response page.

Interfaces to Databases (IDS-3) 